\title{
Development of a homologous radioimmunoassay for a gonadotropin of the gilthead seabream, Sparus aurata
}

\author{
Y. Zohar ${ }^{\mathrm{a}}$, B. Breton ${ }^{\mathrm{b}}$, E. Sambroni ${ }^{\mathrm{b}}$, A. Fostier ${ }^{\mathrm{b}}$, M. Tosky ${ }^{\mathrm{a}}$, G. Pagelson ${ }^{\mathrm{a}}$ and \\ D. Leibovitz ${ }^{\mathrm{a}}$ \\ ${ }^{\mathrm{a}}$ National Center for Mariculture, Israel Oceanographic and Limnological Research Institute, P.O.B. \\ 1212, Eilat (Israel) \\ ${ }^{b}$ Laboratory of Fish Physiology, INRA, Campus de Beaulieu, Rennes (France)
}

(Accepted 25 September 1989)

\begin{abstract}
Zohar, Y., Breton, B., Sambroni, E., Fostier, A., Tosky, M., Pagelson, G. and Leibovitz, D., 1990. Development of a homologous radioimmunoassay for a gonadotropin of the gilthead seabream, Sparus aurata. Aquaculture, 88: 189-204.

A glycoproteic gonadotropin ( $\mathrm{GtH}$ ) was partially isolated from pituitaries of sexually mature Sparus aurata and used for the development of its radioimmunoassay (RIA). Two major chromatographic steps were used for the isolation of the GtH: affinity chromatography on Concanavalin ASepharose and gel filtration on Ultrogel ACA-54. The Sparus aurata GtH (SaGtH) was located using both a bioassay of in vitro production of $17 \alpha$-hydroxy, $20 \beta$-dihydroprogesterone $(17 \alpha, 20 \beta$-OHP) by follicles of rainbow trout and a RIA for the $\beta$ sub-unit of salmon GtH ( $\operatorname{sGtH} \beta$ ). The isolated SaGtH was used for raising antibodies and as a standard. A bighly purified preparation of SaGtH- ${ }^{125} \mathrm{I}$ was obtained by running the radiolabel through Sephadex G-50 and polyacrylamide gel electrophoresis (PAGE). The RIA was found to be sensitive $(0.3 \mathrm{ng} / \mathrm{ml}$ ), precise (intra-assay variability of 10 $11 \%$ ), and specific for GtH of Sparidae species (Sparus aurata and Sparus latus). It showed a poor cross-reactivity with pituitary extracts of several other marine fish. Using this RIA, a GnRH-induced $\mathrm{SaGtH}$ secretion was monitored both in vivo and in vitro.
\end{abstract}

\section{INTRODUCTION}

The reproductive physiology of the gilthead seabream, Sparus aurata, represents both fundamental and applied interests. Fundamental, because $S p a-$ rus aurata is a protandrous hermaphrodite species with a non-synchronous ovarian development (Zohar et al., 1978, 1984), and applied because, with other species of its family, it is a major candidate for commercial fish farming. However, when Sparus aurata and related species are raised in certain fish-holding facilities, spawning is impaired (Barnabé and René, 1973; Gordin and Zohar, 1978; Zohar and Gordin, 1979). The study of the reproduc- 
tive physiology in species belonging to the family Sparidae has been limited due to the absence of a technology for the measurement of the fish's gonadotropin $(\mathrm{GtH})$.

A glycoproteic $\mathrm{GtH}$, involved in the induction of oocyte maturation and ovulation, has been purified from pituitaries of different fish species, and used for the development of its own radioimmunoassay: common carp (BurzawaGerard, 1971), chinook salmon (Breton et al., 1978), chum salmon (Idler et al., 1975; Suzuki et al., 1988a,c), rainbow trout (Breton et al., 1976), sturgeon (Burzawa-Gerard et al., 1975), tilapia (Bogomolnaya-Bass and Yaron, 1988 ). Cross-reactivity tests carried out with some of these RIA's showed that fish GtHs have a high degree of immunological species specificity (Bye et al., 1980). Using RIA for carp or salmon GtH or for their $\beta$ sub-units, it was possible to demonstrate immunoreactive (ir) GtH in pituitary extracts of Sparus aurata (Breton et al., 1984). However, due to their heterologous nature, these RIAs were not sensitive enough to detect GtH in plasma of Sparus aurata. The present paper describes the partial isolation of a glycoproteic $\mathrm{GtH}$ from pituitaries of Sparus aurata collected during the breeding season, and the development of its homologous RIA.

MATERIALS AND METHODS

Partial preparation of Sparus aurata $G t H$

Around 1500 pituitaries were collected from female and male Sparus aurata during the breeding season (December to March). The pituitaries were immediately frozen in liquid nitrogen and subsequently lyophilized. Lyophilized pituitaries were extracted in $0.05 M$ Tris- $\mathrm{HCl}, \mathrm{NaCl} 0.5 M$ buffer at $\mathrm{pH}$ 7.8. The extract was submitted to affinity chromatography on a Concanavalin A-Sepharose (Pharmacia, Uppsala ) column $(2.5 \times 30 \mathrm{~cm})$ equilibrated with the above buffer containing $1 \mathrm{~m} M$ each of $\mathrm{MgCl}_{2}, \mathrm{CaCl}_{2}$, and $\mathrm{MnCl}_{2}$. After elution of the non-retained fraction, the retained glycoproteins were eluted from the gel by adding $0.15 \mathrm{M}$ of alpha-D-mannoside to the precedent buffer. The glycoproteic fraction was concentrated and re-run on Concanavalin ASepharose using the same procedure. After concentration, the final glycoproteic extract was further fractionated on an Ultrogel ACA 54 (LKB, Turku) column $(100 \times 1.6 \mathrm{~cm})$ using $0.05 \mathrm{M}$ Tris- $\mathrm{HCl}$ buffer at $\mathrm{pH} 7.8$ at $20 \mathrm{ml} / \mathrm{h}$. The gonadotropic bioactivity and immunoactivity of the resulting fractions were determined (see below). The fraction containing the maximal gonadotropic activity was used for the production of antisera and as a standard in the RIA. 


\section{Assay for gonadotropic bioactivity}

The gonadotropic bioactivity was estimated by measuring the potential of the studied fractions to stimulate the production of $17 \alpha$-hydroxy, $20 \beta$-dihydroprogesterone by in vitro-incubated follicles of rainbow trout, as described by Fostier and Jalabert (1984).

\section{Assay for gonadotropic immunoactivity}

The immunoreactive content of the studied fractions was determined in equivalent salmon (s) GtH units using a radioimmunoassay for $\beta$ sub-unit of salmon GtH. Labeled $\beta$ sub-unit of sGtH ( $\mathrm{sGtH} \beta)$, standard sGtH and antiserum directed against $\mathrm{sGtH} \beta$ were used. Breton et al. (1984) demonstrated the validity of this system for the quantification of immunoreactive gonadotropin of Sparus aurata. Each tested fraction was serially diluted to obtain a displacement curve in the above system, on the basis of which the immunoreactive equivalent $\mathrm{sGtH}$ content of the fractions was determined.

\section{Production of antiserum against $\mathrm{SaGtH}$}

Antiserum against the $\mathrm{SaGtH}$ was raised by injecting the fraction with maximal gonadotropic activity $(\# 31)$ into rabbits. Each intradermal injection consisted of $100 \mu \mathrm{g}$ of SaGtH emulsified in $1 \mathrm{ml}$ of a mixture containing $8 \%$ $\mathrm{NaCl}$ and complete Freund adjuvant $(1: 1)$.

\section{Iodination of SaGtH}

Iodination of SaGtH was carried out in $0.05 \mathrm{M}$ phosphate buffer at $\mathrm{pH}$ 7.5. Five micrograms $(18 \mu \mathrm{l})$ of the fraction containing the highest gonadotropic activity ( $\# 31$ ) were incubated with $500 \mu \mathrm{Ci}(10 \mu \mathrm{l})$ of $\mathrm{Na}^{125} \mathrm{I}$ (Amersham, IMS-30) and $50 \mu \mathrm{g}(10 \mu \mathrm{l})$ of Chloramine $\mathrm{T}$ for $4 \mathrm{~min}$ on ice. The iodination was stopped by the addition of $90 \mu \mathrm{g}(10 \mu \mathrm{l})$ of sodium metabisulfite and 125 $\mu \mathrm{g}(25 \mu \mathrm{l})$ of $\mathrm{KI}$ were then added to the iodination mixture.

\section{Purification of the SaGtH- ${ }^{125} \mathrm{I}$}

The free iodide was separated from the labeled hormone by gel filtration on a Sephadex G-50 (Pharmacia) column $(1 \times 20 \mathrm{~cm})$ pre-equilibrated with $0.05 M$ sodium barbital buffer at $\mathrm{pH} 8.6$, containing $0.1 \%$ BSA and $0.01 \%$ thimerosal. Elution of the iodination mixture was carried out with the same buffer and 200- $\mu \mathrm{l}$ fractions were collected. The fractions containing the highest immunoprccipitable radioactivity (using an excess of antiserum directed against $\mathrm{SaGtH}$ ) were further fractionated by polyacrylamide gel electropho- 
resis (PAGE). After adding to each fraction $20 \mu \mathrm{l}$ of saturated sucrose solution containing bromophenol blue, they were each applied to an individual tube $(0.6 \times 12 \mathrm{~cm})$ containing $7.5 \%$ polyacrylamide. Fractionation was achieved by applying $2.5 \mathrm{~mA} /$ tube between $0.04 \mathrm{M}$ Tris- $\mathrm{HCl}$ buffer at $\mathrm{pH}$ 8.9 and $0.12 \mathrm{M}$ Tris- $\mathrm{HCl}$ buffer at $\mathrm{pH} \mathrm{8.07}$. At the end of the migration the gels were removed from the tubes and cut into slices of $1.5 \mathrm{~mm}$ each, the radioactive content of which was counted. The slices corresponding to single peaks of the radioelectrophorogram were pooled and their radiolabeled content was extracted by homogenization in $2.5 \mathrm{ml}$ of $0.025 \mathrm{M}$ sodium barbital buffer at $\mathrm{pH} 8.6$, containing $0.1 \%$ BSA and $0.01 \%$ thimerosal. The radio-iodinated SaGtH ( $\left.\mathrm{SaGtH}^{-125} \mathrm{I}\right)$ was located by incubating the different extracts with excess quantities of two antisera directed against $\beta$ sub-unit of carp (c) $\mathrm{GtH}$ and two antisera directed against $\beta$ sub-unit of sGtH. The percentage of the radioactivity bound to the antibodies out of the total radioactivity was determined.

\section{Procedures of radioimmunoassay}

A double antibody RIA was used. The assay buffer was $0.025 \mathrm{M}$ sodium barbital at $\mathrm{pH} 8.6$, containing $0.1 \% \mathrm{BSA}$ and $0.01 \%$ thimerosal. This buffer was also used for the dilution of standard $\mathrm{SaGtH}$ and unknowns (plasma and pituitary extracts). Duplicate $50-\mu 1$ samples of standard or unknowns were loaded into 3-ml plastic tubes. Antiserum against $\mathrm{SaGtH}$ was added $(50 \mu \mathrm{l})$ to all tubes except blanks at a final concentration of 1:300 000. At this concentration the antibody binds $30-35 \%$ of the labeled ligand in the absence of unlabeled hormone. The antibody was diluted in an assay buffer containing $1 \%$ normal rabbit serum. The volume in all tubes was adjusted to $400 \mu \mathrm{l}$. After $24 \mathrm{~h}$ of incubation at $4^{\circ} \mathrm{C}, 100 \mu \mathrm{l}$ of iodinated $\mathrm{SaGtH}$ (around $10000 \mathrm{cpm}$ ) were added to all tubes and the incubation was continued for a further $72 \mathrm{~h}$ at $4^{\circ} \mathrm{C}$. At that time $100 \mu \mathrm{l}$ of goat anti-rabbit gamma-globulin were added to all tubes (diluted in assay buffer) to a final dilution of $1: 90$. After $24 \mathrm{~h}$ incubation at room temperature (around $20^{\circ} \mathrm{C}$ ), $2.5 \mathrm{ml}$ of $0.025 \mathrm{M}$ sodium barbital buffer at $\mathrm{pH} 8.6$ was added to all tubes, which were then centrifuged for $30 \mathrm{~min}$ at $2500 \times g$ and at $4{ }^{\circ} \mathrm{C}$. The supernatant was aspirated and the pellet counted in an LKB gamma counter. A log-logit transformation was used for calculation of results. The intra-assay variability was estimated by repetitive measurements, in each of the RIAs, of SaGtH concentrations in two pools of plasma, containing high and low levels of the hormone.

\section{Validation of RIA}

Tests with pituitaries of different fish

Pituitaries of gilthead seabream (Sparus aurata), seabass (Dicentrarchus labrax), rabbitfish (Siganus argentius), and grey mullet (Mugil cephalus) 
were removed from freshly killed adult fish reared in sea-water ponds of the National Center for Mariculture in Eilat. Lyophilized pituitaries of Chinese seabream, Sparus latus, were obtained by Dr. H.R. Lin from adult cage-cultured fish in the Chinese sea. Fresh or lyophilized pituitaries were individually homogenized in $1 \mathrm{ml}$ of RIA buffer using a glass homogenizer. The homogenate was centrifuged $\left(20 \mathrm{~min}, 2500 \times g, 4^{\circ} \mathrm{C}\right)$ and the supernatant was serially diluted in the assay buffer (to final dilutions of 1:100 through $1: 100000$ ) for displacement tests in the RIA for SaGtH. Slopes of the loglogit transformed displacement curves were compared to that of the standard curve by analysis of covariance ( $F$ test).

\section{Effects of gonadotropin-releasing hormones}

Experimental fish. Adult 3-4-year-old female Sparus aurata, $500-800 \mathrm{~g}$ body weight, were used. They were held in outdoor tanks of $20 \mathrm{~m}^{3}$ at densities of $10 \mathrm{~kg} / \mathrm{m}^{3}$. Fish were exposed to natural photoperiod and to water temperatures of $20^{\circ} \mathrm{C} \pm 2$. They were fed once a day ad libitum with artificial food pellets. A day before experimentation, fish undergoing final stages of vitellogenesis were selected and transferred to $0.6-\mathrm{m}^{3}$ tanks. Oocyte developmental stages were determined by microscopic examination of an ovarian biopsy, according to Zohar and Gordin (1979).

In vivo experiment. Two groups of eight females each were injected in the dorsal musculature with either $7.5 \mu \mathrm{g} / \mathrm{kg}$ BW of [D-Ala ${ }^{6}-$ Pro $^{9} \mathrm{NET}$ ]-LHRH (Sigma Chemicals, St. Louis, MO) or with $0.9 \%$ saline. The injected volume was $500 \mu \mathrm{l} / \mathrm{kg} \mathrm{BW}$. Blood $(600 \mu \mathrm{l})$ was sampled from the caudal vessels of all fish immediately before and at $1.5,4,8,12,24$, and $48 \mathrm{~h}$ after the injection. Blood samples were centrifuged at $2500 \times g$ for $30 \mathrm{~min}$ at $4^{\circ} \mathrm{C}$ and plasma was stored at $-70^{\circ} \mathrm{C}$ for measurement of SaGtH by RIA. Two additional females were injected with [D-Ala ${ }^{6}-$ Pro $^{9}$ NET ]-LHRH as above and bled at 3 and $6 \mathrm{~h}$ thereafter. The plasmas separated from these samples were serially diluted (1:2 through $1: 32)$ for displacement tests in the RIA for SaGtH.

In vitro experiments. An open superfusion system for pituitary fragments was used, as described by Zohar et al. (1989). Pituitary fragments were exposed to 5-min pulses of increasing concentration $\left(10^{-10}\right.$ to $\left.10^{-7} M\right)$ of native sGnRH (Bachem, Bubendorf). The effluent of the superfusion chambers (at $15 \mathrm{ml} / \mathrm{h}$ ) was collected at 10 -min intervals and stored at $-30^{\circ} \mathrm{C}$ for measurements of SaGtH by RIA. 


\section{RESULTS}

\section{Preparation of Sparus aurata gonadotropin}

Buffer extraction of Sparus aurata pituitaries resulted in $350 \mathrm{mg}$ of proteins, from which $27 \mathrm{mg}$ were obtained in the glycoproteic fraction following two separations on Concanavalin A-Sepharose. Fractionation of the glycoproteins by gel-filtration chromatography on Ultrogel ACA 54 is shown in Fig. 1. A total of $2.8 \mathrm{mg}$ proteins of molecular weight included between 22 $\mathrm{kDa}$ and $40 \mathrm{kDa}$ were obtained. Of this quantity, only $77.9 \mu \mathrm{g}$ equivalent immunoreactive sGtH and $99.3 \mu \mathrm{g}$ equivalent bioactive sGtH were measured. The maximal gonadotropic biological and immunological activity was found in the fraction corresponding to molecular weight of about $30 \mathrm{kDa}$ (fraction 31 , Fig. 1). Using the in vitro bioassay of $17 \alpha, 20 \beta$-OHP production by follicles of rainbow trout, this fraction was found to contain $58 \mathrm{ng} / \mu \mathrm{g}$ protein of equivalent sGtH (Fig. 1), which corresponds to a total of $23.2 \mu \mathrm{g}$ of equivalent sGtH. The anti-sGtH $\beta$-sGtH $\beta{ }^{-125}$ I RIA system showed somewhat lower equivalent $\mathrm{sGtH}$ activity, that is $41.5 \mathrm{ng} / \mu \mathrm{g}$ protein (Fig. 1), which corresponds to a total of $16.6 \mu \mathrm{g}$ of equivalent sGtH. The slope of the log-logit

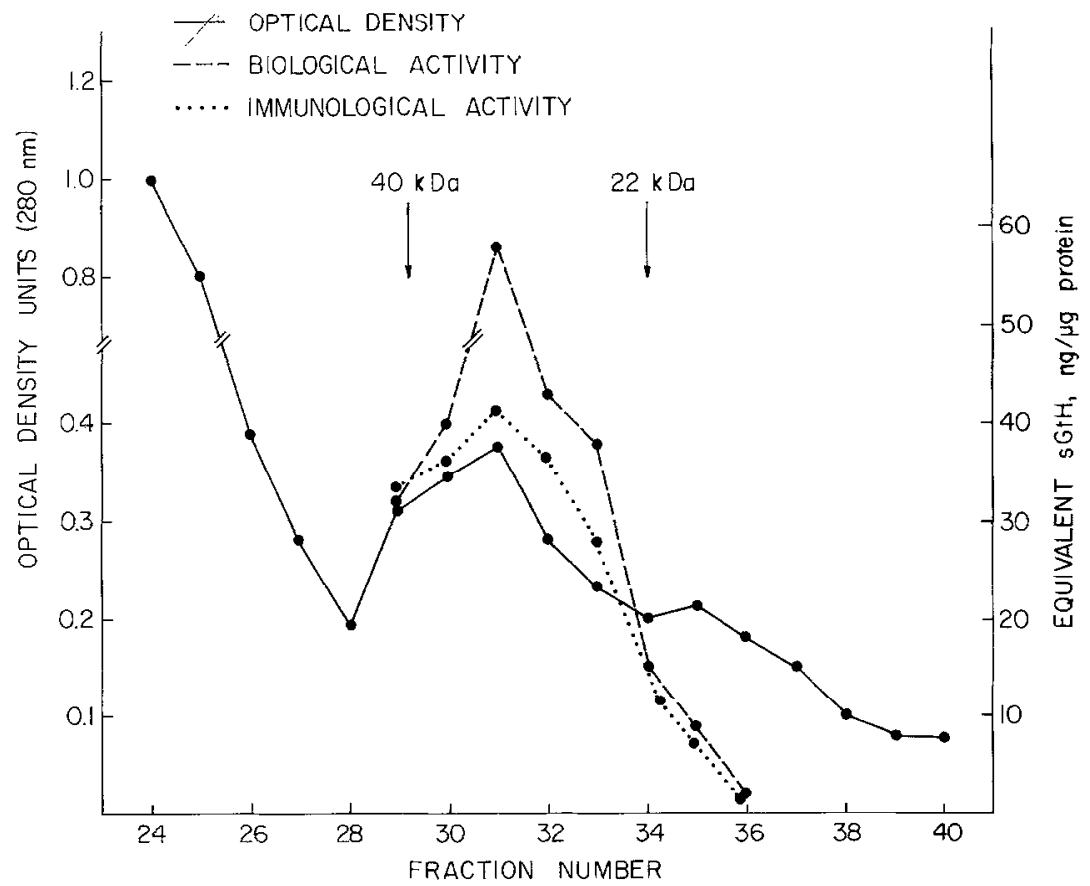

Fig. 1. Gel-filtration chromatography of the glycoproteins obtained from pituitarics of Sparus aurata on Ultrogel ACA 54. Optical density and gonadotropic bioactivity and immunoactivity of the different fractions are shown. 
transformed displacement curve obtained with serial dilutions of fraction 31 in this system was -1.12 as compared to -1.10 of the standard curve. Therefore fraction 31 was assumed to contain the highest content of $\mathrm{SaGtH}$ and was used for the production of antibodies, as a standard and for radio-iodination. This fraction is further referred to as $\mathrm{SaGtH}$.

\section{Production of pure $\mathrm{SaGtH}-{ }^{125} \mathrm{I}$}

Iodination of the SaGtH (fraction 31 ) resulted in 79 to $85 \%$ of the radioactivity associated with the early migrating peak on Sephadex G-50, which contains the SaGtH immunoreactivity. Specific activity was around $80 \mu \mathrm{Ci} /$ $\mu \mathrm{g}$ protein. PAGE of the post-Sephadex G-50 iodinated fractions showed that the radiolabeled material was composed of a major peak (containing an average of $85 \%$ of the radioactivity) and two minor ones (Fig. 2). The percent radioactivity of each peak which binds to excess amounts of different antisera is shown in Table 1. All three peaks bind to the antiserum directed against $\mathrm{SaGtH}$. This antiserum binds $95 \%$ of the radioactivity associated with the major peak (no. 2 ) and $23 \%$ and $48 \%$ of the radioactivity associated with peaks no. 1 and 3, respectively. However, the antisera directed against $\beta$ subunits of salmon and carp $\mathrm{GtH}$ reacted more specifically with the radio-iodinated peaks nos. 2 and 3 (Table 1 ). Those antisera bound $21-40 \%$ of the

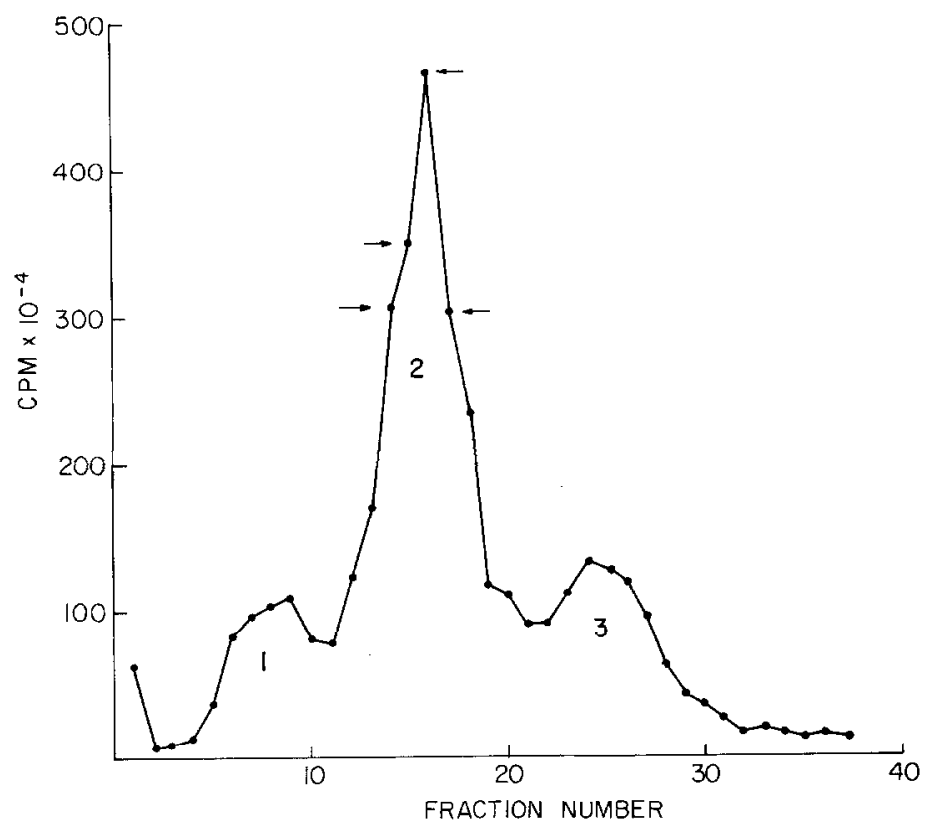

Fig. 2. Polyacrylamide gel electrophoresis of iodinated SaGtH. Fraction numbers on the abscissa correspond to $1.5-\mathrm{mm}$ gel slices. The arrows indicate the fractions (slices) from which the SaGtH- ${ }^{-125}$ I was extracted for RIA. 


\section{TABLE 1}

Percentage of the total radioactivity associated with the three PAGE peaks (Fig. 2 ) which was bound to antisera directed against $\mathrm{SaGtH}$ and $\beta$ sub-units of carp and salmon $\mathrm{GtH}$

\begin{tabular}{lrrr}
\hline Antiserum & \multicolumn{3}{l}{ Peak number } \\
\cline { 2 - 4 } & \multicolumn{1}{c}{1} & \multicolumn{1}{c}{2} & \multicolumn{1}{c}{3} \\
\hline SaGtH & 23 & 85 & 48 \\
$\beta$ Carp GtH-1 & 2 & 23 & 8 \\
$\beta$ Carp GtH-2 & 0 & 21 & 6 \\
$\beta$ Salmon GtH-1 & 2 & 36 & 12 \\
$\beta$ Salmon GtH-2 & 0 & 40 & 15 \\
\hline
\end{tabular}

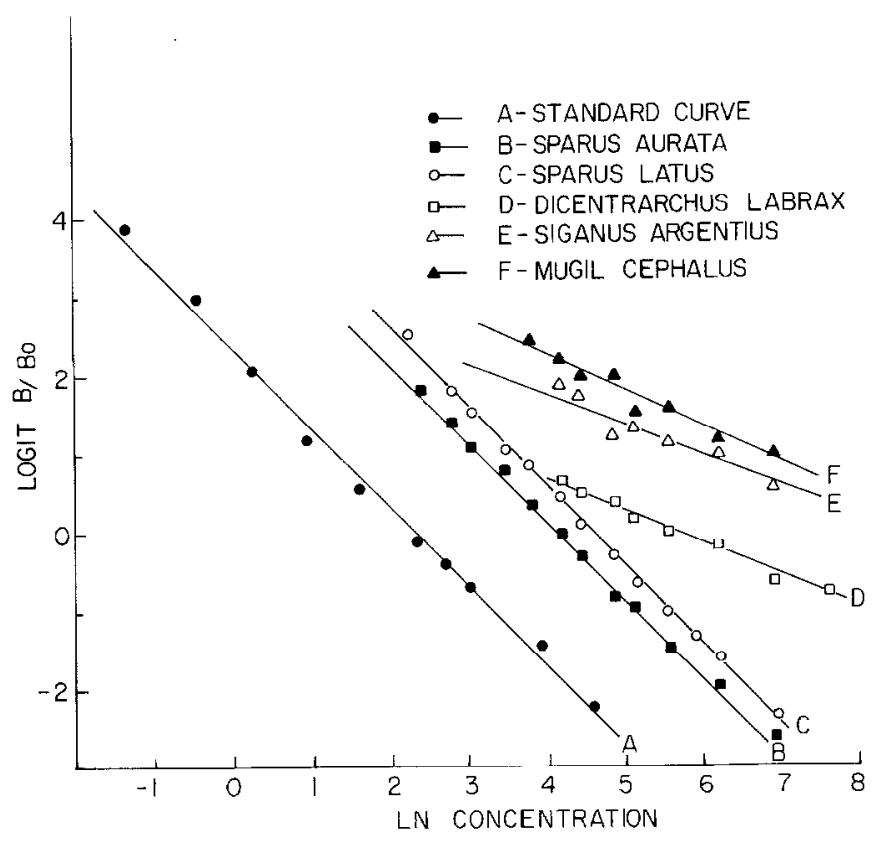

Fig. 3. Displacement curves for SaGtH standard (A) and for serial dilutions of pituitary extracts of different marine fish species (B-F). In order to draw all curves on the same scale the concentration of the standards was multiplied by 10 .

radioactivity associated with peak no. $2,6-15 \%$ of the radioactivity associated with peak no. 3 , and only $0-2 \%$ of the radioactivity associated with peak no. 1 (Table 1). The PAGE peak no. 2 (Fig. 2) was assumed to be a pure preparation of SaGtH $-{ }^{125} \mathrm{I}$ and was further used for SaGtH radioimmunoassay.

Displacement tests with SaGtH and pituitary extracts

Using an antiserum raised against fraction 31 of the ACA 54 gel-filtration

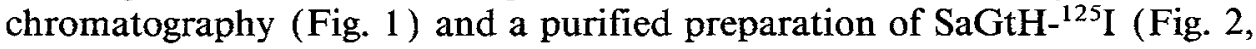


fraction 2), increasing concentrations $(0.3-100 \mathrm{ng} / \mathrm{ml}$ ) of SaGtH (fraction 31 ) resulted in a linear log-logit displacement curve (Fig. 3A), the slope of which was -1.04 . The coefficient of regression of this curve was 1.0. Displacement of $50 \%$ of the radioactive ligand from the antibody $\left(B / B_{0}=50 \%\right)$ was obtained with $5-10 \mathrm{ng} / \mathrm{ml} \mathrm{SaGtH}$ (corresponding to $100-200 \mathrm{pg} /$ tube). Serial dilutions of pituitary extracts of Sparus aurata resulted in a displacement curve parallel to the standard curve (Fig. 3B, slope -1.03). The potential of pituitary extracts of an additional four marine fish species to displace the $\mathrm{SaGtH}-{ }^{125}$ I from its specific antiserum was tested. Only serial dilutions of pituitary extract of a sparid fish, Sparus latus, resulted in a displacement curve parallel to the standard curve and to the displacement line obtained with pituitary extract of Sparus aurata (Fig. 3C, slope -1.01). Serial dilutions of pituitary extracts of seabass, Dicentrarchus labrax (Fig. 3D), rabbitfish ( $\mathrm{Si}$ ganus argentius (Fig. 3E), and grey mullet, Mugil cephalus (Fig. 3F) resulted in displacement curves the slopes of which $(-0.41,-0.48$, and -0.56 , respectively) were significantly different $(P<0.01)$ from those obtained with either the standard SaGtH or with pituitary extracts of Sparus aurata or Sparus latus.

In vivo effect of gonadotopin-releasing hormone

Plasma of female Sparus aurata sampled at different times after the administration of $7.5 \mu \mathrm{g} / \mathrm{kg}$ BW of [D-Ala $\left.{ }^{6}-\mathrm{Pro}^{9} \mathrm{NET}\right]-\mathrm{LHRH}$ displaced the SaGtH-

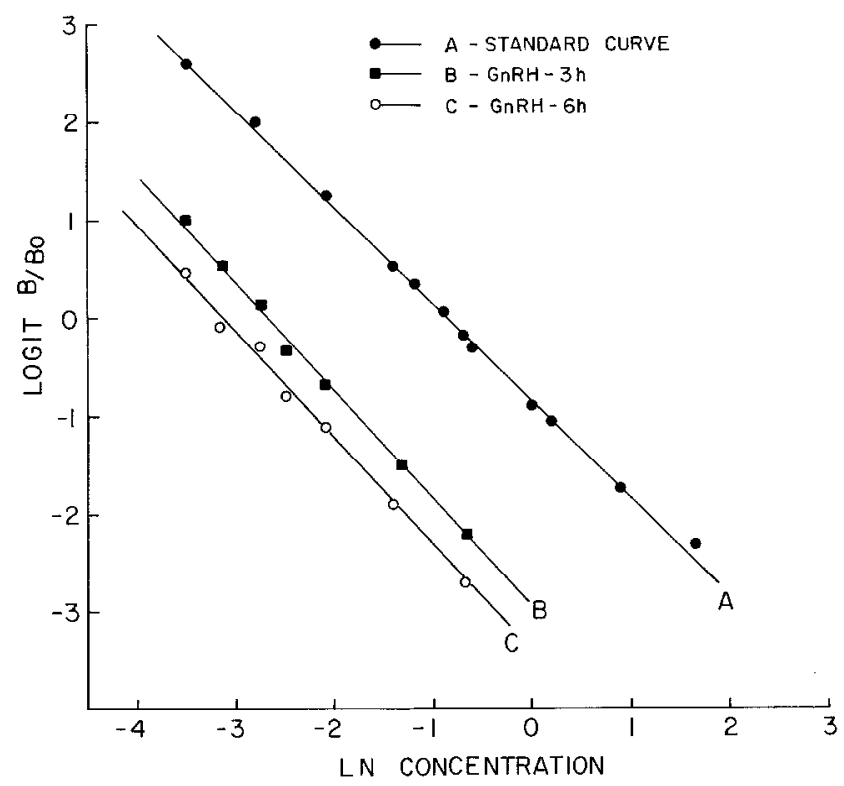

Fig. 4. Displacement curves for SaGtH standard (A) and for serial dilutions of plasma sampled from a female Sparus aurata $3 \mathrm{~h}(\mathrm{~B})$ and $6 \mathrm{~h}$ (C) after its injection with [D-Ala ${ }^{6}-\mathrm{Pro}^{9} \mathrm{NET}$ ]$\mathrm{LHRH}$ at $7.5 \mu \mathrm{g} / \mathrm{kg} \mathrm{BW}$. 


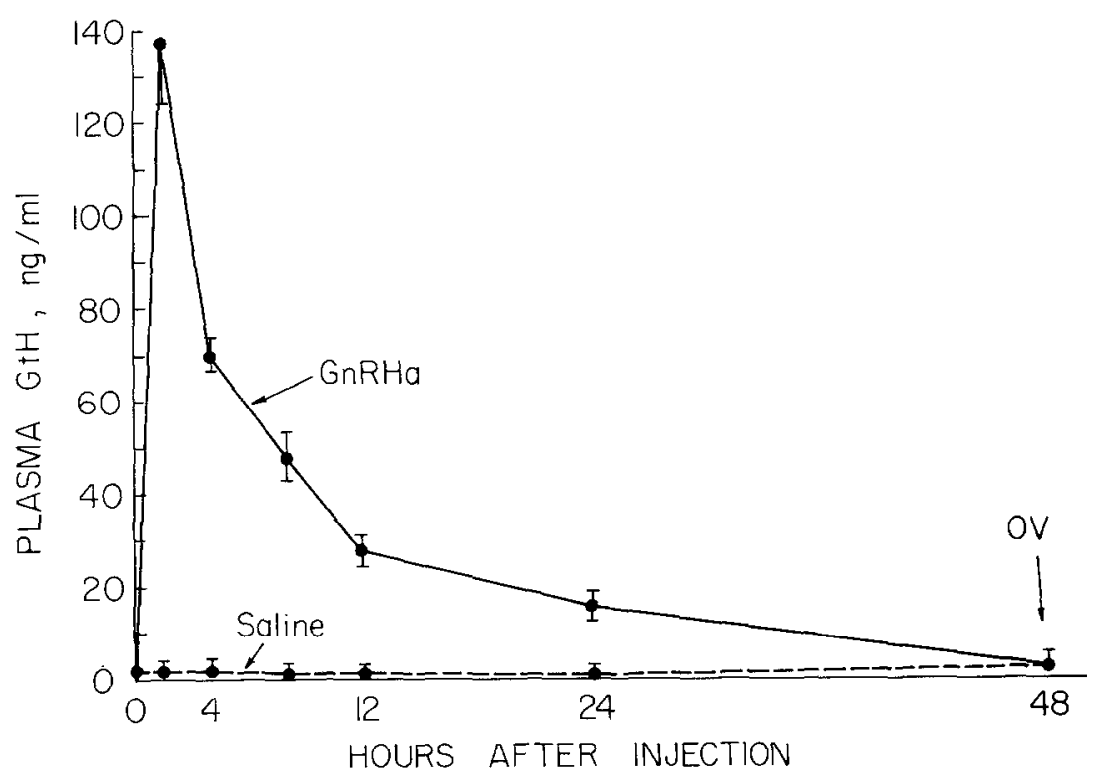

Fig. 5. Plasma levels of $\mathrm{SaGtH}$ (mean \pm s.e.m.) in female Sparus aurata before and at different times after the injection of either [D-Ala - Pro ${ }^{9}$ NET]-LHRH (at $7.5 \mu \mathrm{g} / \mathrm{kg} \mathrm{BW}$ ) or saline (at $0.5 \mathrm{ml} / \mathrm{kg} \mathrm{BW}$ ). $\mathrm{OV}=$ ovulation.

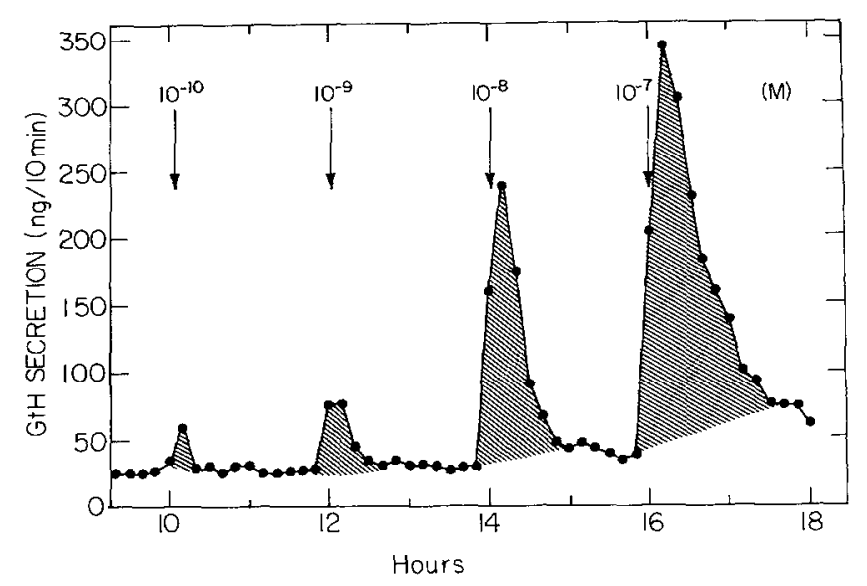

Fig. 6. Levels of SaGtH in incubation medium leaving a superfusion cell in which pituitary fragments were exposed to 5 -min pulses of increasing concentration of sGnRH.

${ }^{125}$ I from its antiserum (Figs. 4, 5). Serial dilutions of these plasmas resulted in log-logit displacement curves parallel to the standard curve (Fig. 4B and $\mathrm{C}$, slopes -1.13 and -1.14 , respectively, as compared to -1.09 for the standard curve). At $3 \mathrm{~h}$ post-GnRHa injection, $50 \%$ displacement was obtained with $1: 24$ dilution of plasma whereas at $6 \mathrm{~h}$ post-GnRHa injection $50 \%$ dis- 
placement was obtained with $1: 14$ dilution of plasma. Non-diluted plasma of females injected with saline showed a slight displacement $\left(B / B_{0}\right.$ ranging from 73 to $94 \%$ ) corresponding to 0.6 to $2.5 \mathrm{ng} / \mathrm{ml}$ of immunoreactive (ir) $\mathrm{SaGtH}$ (Fig. 5).

The administration of (D-Ala - Pro $\left.{ }^{9} \mathrm{NET}\right)$-LHRH resulted in an intensive surge of irSaGtH (Fig. 5), reaching peak levels of $137 \pm 13 \mathrm{ng} / \mathrm{ml}(\bar{x} \pm$ s.e.m.) at $1.5 \mathrm{~h}$ after the injection. The levels of irSaGtH decreased continuously thereafter and reached pre-injection values at $48 \mathrm{~h}$, at which time all injected females were ovulated (Fig. 5). The levels of irSaGtH in saline-injected females remained low throughout the experimental period and their vitellogenic oocytes underwent atresia.

\section{In vitro effect of gonadotropin-releasing hormone}

The exposure of in vitro-superfused pituitary fragments to 5-min pulses of sGnRH at a concentration as low as $10^{-10} M$ induced an immediate release of irSaGtH to the superfusion medium (Fig. 6). Increasing concentrations of sGnRH, from $10^{-10}$ to $10^{-7} \mathrm{M}$, resulted in a dose-dependent increase in the secretion of irSaGtH by the pituitary fragments.

\section{Precision of radioimmunoassay}

Repetitive measurements (5-6/assay) of a plasma pool containing low levels of irSaGtH $(3-5 \mathrm{ng} / \mathrm{ml})$ showed an intra-assay variability of $11 \%$ (mean cv for six assays) ranging from 9.3 to $13.4 \%$. For higher levels of ir$\mathrm{SaGtH}(20-25 \mathrm{ng} / \mathrm{ml}$ ) intra-assay variability was $9.8 \%$ (mean of eight assays) ranging from 6.7 to $12.5 \%$.

\section{DISCUSSION}

A glycoproteic gonadotropin was partially isolated from pituitaries of Sparus aurata by two major chromatographic steps: affinity chromatography on Concanavalin A-Sepharose and gel filtration on Ultrogel ACA 54. Due to the low content of the measured immunoreactive $(77.9 \mu \mathrm{g})$ and bioactive $(99.3$ $\mu \mathrm{g})$ gonadotropin in the fractions obtained from the ACA 54 column, further purification steps, such as ion-exchange chromatography, were excluded. The low content of measured gonadotropic activity probably reflects the heterologous nature of the immunoassay and bioassay used in the present work. The $\beta$ sub-unit of fish gonadotropins has been shown to represent a relatively low degree of immunological species specificity (Burzawa-Gerard and Kerdelhué, 1978; Dufour et al., 1979; Burzawa-Gerard et al., 1980). It is a common practice to use heterologous RIA based on $\beta$ sub-units of fish gonadotropins ( usually carp or salmon ), in combination with heterologous bioassay, to evaluate the gonadotropic content throughout a purification procedure of fish gonadotropins (Dufour et al., 1983; Goos et al., 1986; review by Idler and Ng, 
1983 ). Both the immunoassay and the bioassay used in the present study have been previously validated for the estimation of gonadotropic activity in Sparus aurata pituitaries (Breton et al., 1984; Fostier and Jalabert, 1984). Of different tested RIA systems for $\beta$ sub-units of fish gonadotropins, the anti$\mathrm{sGtH} \beta-\mathrm{sGtH} \beta-_{-1}^{125}$ I was found to be the most appropriate for measuring immunoreactive GtH in Sparus aurata, and was thus selected for the present study. In fact, the bioassay and the immunoassay resulted in parallel and relatively close estimates of the GtH content along the ACA 54 gel-filtration chromatogram (Fig. 1). However, due to their heterologous nature, both assays considerably underestimate the $\mathrm{SaGtH}$ content in the tested fractions. Using the SaGtH RIA, we have measured levels of 5 to $30 \mu \mathrm{g} \mathrm{GtH}$ per pituitary in male and female Sparus aurata at the breeding season. This implies that the 1500 pituitaries used for the present purification contained a total of 7.5 to $45 \mathrm{mg}$ of SaGtH. The assays used for estimating gonadotropic activity showed only 77.9 to $99.3 \mu \mathrm{g}$ of $\mathrm{GtH}$ at the post-ACA 54 chromatography. A further loss of $\mathrm{GtH}$ activity on ion exchange (as reported by Burzawa-Gerard et al., 1975; Breton et al., 1976) would have resulted in non-detectable quantities of gonadotropic activity.

The partially purified SaGtH obtained might be contaminated by other glycoproteic hormones. Recently Suzuki et al. (1988a) demonstrated the existence of two glycoproteic GtHs in chum salmon pituitary. GtH I, which might be a novel fish gonadotropin, has a molecular weight of $50 \mathrm{kDa}$ (Suzuki et al., 1988a). GtH II, the molecular weight of which is $36 \mathrm{kDa}$, is probably the previously isolated maturational GtH (Suzuki et al., 1988b). GtH II is the dominant gonadotropin in the pituitaries of spermiating male and ovulated female salmon (Suzuki et al., 1988c). If two distinct GtHs are also present in Sparus aurata, the GtH isolated in the present work probably corresponds to the maturational GtH II, as its molecular weight is around $30 \mathrm{kDa}$ and it was purified from pituitaries of females and males undergoing final stages of gametogenesis. Contamination with GtH I is thus probably limited. Using the RIA for SaGtH, we detected very low levels of the hormone during vitellogenesis, while oocyte maturation and ovulation were shown to be accompanied by a GtH surge (Zohar et al., 1988 and unpubl.). This finding suggests that the gonadotropin which our RIA measures is the maturational GtII II and thus further supports the assumption that the $\mathrm{SaGtH}$ is not or only minimally contaminated with GtH I.

The SaGtH preparation used for the development of the RIA is included in only one fraction of the ACA 54 chromatography (fraction 31). Thus the possibility of its contamination by proteins of other molecular weight is low. However, teleost maturational GtH and thyrotropin (TSH) were shown to be glycoproteins of relatively similar molecular weight ( $\mathrm{Ng}$ et al., 1982; Swanson et al., 1987). These hormones have been separated from each other by ion exchange chromatography ( $\mathrm{Ng}$ et al., 1982) or chromatofocusing (Swan- 
son et al., 1987). Therefore, the SaGtH might be contaminated by TSH. As fish TSH has been shown to be a more basic protein than $\mathrm{GtH}$, and thus to migrate at a different rate from GtH on PAGE (Swanson et al., 1987; Burzawa-Gerard, 1974a), we used PAGE to obtain highly purified radio-iodinated SaGtH. PAGE of the iodinated post-ACA $54 \mathrm{SaGtH}$ yielded a major peak (no. 2 in Fig. 2) which showed a high degree of binding to the SaGtH antiserum and to four antisera directed against $\beta$ sub-units of carp and salmon GtH (Table 1). This major peak was preceded by a minor peak and followed by another (Fig. 2, peaks no. 1 and 3 ). Both small peaks reacted with the antiSaGtH antiserum (23\% for peak 1 and $48 \%$ for peak 3 ). While peak no. 1 showed almost no binding to the GtH $\beta$ antisera $(0-2 \%)$, peak no. 3 contained material which cross-reacted with those antisera ( 6 to $15 \%$ ). Because (1) antisera directed against $\beta$ sub-units of GtH have been shown to be specific to $\mathrm{GtH}$ and to its $\beta$ sub-units and to have no cross-reactivity with fish TSH (Schreibman and Margolis-Kazan, 1979), and (2) the $\beta$ sub-units of fish GtHs migrate faster towards the cathode than the whole molecule (Burzawa-Gerard et al., 1976; Breton, 1981), it is concluded that the major PAGE peak no. 2 represents the pure $\mathrm{SaGtH}$. The fact that this peak contains around $85 \%$ of the radioactivity suggests that the post-ACA 54 preparation obtained is mainly composed of $\mathrm{SaGtH}$ and that the antiserum is mainly directed against this hormone. As peak no. 1 represents a relatively basic protein (as indicated by its short distance from the anode), it is suggested that it might contain the TSH. The amount of radioactivity associated with this peak suggests that the post-ACA $54 \mathrm{SaGtH}$ might be contaminated with $5-10 \%$ of TSH. The relatively high binding of peak 3 to $\mathrm{SaGtH}$ antiserum, its binding to $\mathrm{GtH} \beta$ antisera, and its longest distance from the anode suggest that this peak contains the $\beta$ sub-unit of SaGtH. The presence of the $\beta$ sub-unit of SaGtH might be the result of dissociation of the GtH on PAGE, as was reported for carp (Burzawa-Gerard, 1974b) and catfish (Goos et al., 1986) gonadotropins. These data and considerations led to a routine production, in each iodination, of a pure SaGtH- ${ }^{125}$ I by extracting the PAGE peak no. 2 out of the gel. The use of this highly purified iodinated ligand allowed the use of a less pure GtH as a standard and of a somewhat composite antibody in the RIA.

The displacement of SaGtH- ${ }^{125}$ I from its antiserum by the non-labeled $\mathrm{SaGtH}$ resulted in a linear log-logit transformed regression line (standard curve ). The lowest detectable level was $0.3 \mathrm{ng} / \mathrm{ml}(15 \mathrm{pg} /$ tube $)$ and the highest level included in the regression line was $100 \mathrm{ng} / \mathrm{ml}(5 \mathrm{ng} /$ tube $)$. Serial dilutions of pituitary extracts of Sparus aurata and Sparus latus resulted in displacement curves parallel to the standard curve, indicating good crossreactivity of the endogenous $\mathrm{GtH}$ of those species with the antiserum. However, serial dilutions of pituitary extracts of other marine fish, seabass ( $D i$ centrarchus labrax), rabbitfish (Siganus argentius), and grey mullet (Mugil cephalus), showed only a poor cross-reactivity with the antiserum. Therefore, 
the RIA established in the present work is probably specific to GtH of fish species belonging to the family Sparidae. Similarly, the RIAs developed for carp and salmon GtH have been used for measurements of $\mathrm{GtH}$ in species belonging to the families Cyprinidae (e.g., Hontela and Peter, 1978) and Salmonidae (e.g., Crim and Idler, 1978; Breton et al., 1983), respectively. Moreover, our data suggest that the GtH of Sparus aurata shows a high degree of immunological species specificity, as was shown earlier for GtHs of other fish species (Bye et al., 1980).

Plasma sampled from female Sparus aurata at different times after the injection of GnRHa displaced labeled SaGtH from its antiserum, the intensity of the displacement being dependent on the timing of the sampling. This corresponded to a GtH surge induced by the GnRHa which lasted $48 \mathrm{~h}$ (Fig. 6) and was followed by oocyte maturation and ovulation. Similar GnRHa-induced $\mathrm{GtH}$ surge leading to ovulation was reported in a variety of fish species (see for review Peter et al., 1986; Zohar, 1988). This, together with the parallelism between the displacement curves obtained with serial dilutions of plasmas of GnRHa-injected females and the standard curve, confirms that our RIA measures gonadotropin in the plasma of Sparus aurata. Moreover, using our RIA, we observed that the exposure of in vitro-superfused pituitary fragments of Sparus aurata to 5-min pulses of sGnRH resulted in immediate, short-term increases in the level of irSaGtH in the superfusion medium. The amount of the SaGtH measured in the superfusion medium was positively correlated with the administered dose of GnRH (Fig. 6). A similar pattern of GnRH-induced GtH release from in vitro-superfused pituitary fragments has been previously described in goldfish (MacKenzie et al., 1984). The above in vivo and in vitro data suggest that our RIA measures the irSaGtH secreted by the pituitary in response to GnRH stimulation. Therefore, the RIA introduced in the present work is a reliable and sensitive homologous RIA of Sparus aurata GtH. This RIA is probably valid for fish species belonging to the family Sparidae.

\section{REFERENCES}

Barnabé, G. and René, F., 1973. Reproduction controlée et production d'alevins chez la daurade Sparus aurata (Linné 1758). C.R. Acad Sci. (Paris) Ser. D., 276: 1621-1624.

Bogomolnaya-Bass, A. and Yaron, Z., 1988. Tilapia gonadotropin: isolation and radioimmunoassay for its quantitative determination. In: Y. Zohar and B. Breton (Editors), Reproduction in Fish - Basic and Applied Aspects in Endocrinology and Genetics, INRA Press, Paris, pp. 109-113.

Breton, B., 1981. A study of salmon (Oncorhynchus tshawytscha) pituitary gonadotropin dissociation. Gen. Comp. Endocrinol., 45: 147-152.

Breton, B., Jalabert, B. and Reinaud, P., 1976. Purification of gonadotropin from rainbow trout (Salmo gairdneri Richardson) pituitary glands. Ann. Biol. Anim. Biochim. Biophys., 16: 25-36. 
Breton, B., Prunet, P. and Reinaud, P., 1978. Sexual differences in salmon gonadotropin. Ann. Biol. Anim. Biochim. Biophys., 18(4): 759-765.

Breton, B., Fostier, A., Zohar, Y., Le Bail, P.Y. and Billard, R., 1983. Gonadotropine glycoprotéique maturante et oestradiol- $17 \beta$ pendant le cycle reproducteur chez la truite fario (Salmo trutta) femelle. Gen. Comp. Endocrinol., 49: 220-231.

Breton, B., Zohar, Y. and Sambroni, 1984. Dosages radioimmunologiques hétérologues de gonadotropines de type glycoprotéiques maturantes de poissons téléostéens. Aquaculture, 40: 307-323.

Burzawa-Gerard, E., 1971. Purification d'une hormone gonadotrope hypophysaire de poisson téléostéen, la carpe (Cyprinus carpio). Biochimie, 53: 545-552.

Burzawa-Gerard, E., 1974a. Etude biologique et biochimique de l'hormone gonadotrope d'un poisson téléostéen, la carpe (Cyprinus carpio L. ). Mem. Mus. Nat. Hist. Nat., Ser. A, 86: 177.

Burzawa-Gerard, E., 1974b. Séparation et réassociation des sous-unités de l'hormone gonadotrope d'un poisson téléostéen, la carpe (Cyprinus carpio L.). C. R. Acad. Sci. (Paris) Ser. D, 279: $1681-1684$.

Burzawa-Gerard, E. and Kerdelhué, B., 1978. Etude par radioimmunologie des propriétés des immunosérums de l'hormone gonadotrope de la carpe (Cyprinus carpio L.) et de ses sousunités. Ann. Biol. Anim. Biochim. Biophys., 18: 773-780.

Burzawa-Gerard, E., Goncharov, B. and Fontaine, Y., 1975. L'hormone gonadotrope hypophysaire d'un poisson chondrostéen, l'esturgeon (Acipenser stellatus P.). I. Purification. Gen. Comp. Endocrinol., 27: 289-295.

Burzawa-Gerard, E., Goncharov, B., Dumas, A. and Fontaine, Y.A., 1976. Further biochemical studies on carp gonadotropin (c-GTH); biochemical and biological comparison of c-GTH and a gonadotropin from Acipenser stellatus Pall. (Chondrostei). Gen. Comp. Endocrinol., 29: 498-505.

Burzawa-Gerard, E., Dufour, S. and Fontaine, Y.A., 1980. Relations immunologiques entre les hormones glycoprotéiques hypophysaires de poissons et de mammifères ainsi qu'entre leurs sous-unités $\alpha$ et $\beta$. Gen. Comp. Endocrinol., 41: 199-211.

Bye, V.J., Breton, B. and Billard, R., 1980. Immunological cross-reaction between pituitary gonadotropin from North Atlantic fish. Gen. Comp. Endocrinol., 41: 130-134.

Crim, L.W. and Idler, D.R., 1978. Plasma gonadotropin, estradiol, and vitellogenin and gonad phosvitin levels in relation to the seasonal reproductive cycles of female brown trout. Ann. Biol. Anim. Biochim. Biophys., 18: 1001-1005.

Dufour, S., Burzawa-Gerard, E. and Fontaine, Y.A., 1979. Evolution des hormones glycoprotéiques hypophysaires: données radioimmunologiques sur les sous-unités de l'hormone gonadotrope de la carpe (Cyprinus carpio L.). C. R. Acad. Sci. (Paris) Ser. D, 289: 137-140.

Dufour, S., Delerue-Le Belle, N. and Fontaine, Y. A., 1983. Development of a heterologous radioimmunoassay for eel (Anguilla anguilla) gonadotropin. Gen. Comp. Endocrinol., 49: 404-413.

Fostier, A. and Jalabert, B., 1984. Mise au point d'un dosage biologique sensible pour la mesure des activités gonadotropes hypophysaires. In: G. Barnabé and R. Billard (Editors), L'Aquaculture du Bar et des Sparides. INRA Press, Paris, pp. 25-31.

Goos, H.J.Th, De Leeuw, R., Burzawa-Gerard, E., Terlou, M. and Richter, C.J.J., 1986. Purification of gonadotropic hormone from the pituitary of the African catfish, Clarias gariepinus (Burchell), and the development of a homologous radioimmunoassay. Gen. Comp. Endocrinol., 63: 162-170.

Gordin, H. and Zohar, Y., 1978. Induced spawning of Sparus aurata (L.) by means of hormonal treatments. Ann. Biol. Anim. Biochim. Biophys., 18: 985-990.

Hontela, A. and Peter, R.E., 1978. Daily cycles in serum gonadotropin levels in the goldfish: effects of photoperiod temperature, and sexual condition. Can. J. Zool., 56: 2430-2442. 
Idler, D.R. and Ng, T.B., 1983. Teleost gonadotropins: isolation, biochemistry, and function. In: W.S. Hoar, D.J. Randall and E.M. Donaldson (Editors), Fish Physiology, Vol. IX A. Academic Press, New York, NY, pp. 187-221.

Idler, D.R., Bazar, L.S. and Hwang, S.J., 1975. Fish gonadotropin(s). II. Isolation of gonadotropin $(\mathrm{s})$ from chum salmon pituitary glands using affinity chromatography. Endocrinol. Res. Commun., 2: 215-235.

MacKenzie, D.S., Gould, D.R., Peter, R.E., Rivier, J. and Vale, W.W., 1984. Response of superfused goldfish pituitary fragments to mammalian and salmon gonadotropin-releasing hormones. Life Sci., 35: 2019-2026.

Ng, T.B., Idler, D.R. and Eales, J.G., 1982. Pituitary hormones that stimulate the thyroidal system in teleost fishes. Gen. Comp. Endocrinol., 48: 372-389.

Peter, R.E., Chang, J.P., Nahorniak, C.S., Omeljaniuk, J.R., Sokolowska, M., Shih, S.H. and Billard, R., 1986. Interactions of catecholamines and $\mathrm{GnRH}$ in regulation of gonadotropin secretion in teleost fish. Rec. Prog. Horm. Res., 42: 513-548.

Schreibman, M. and Margolis-Kazan, H., 1979. The immunocytochemical localization of gonadotropin, its subunits, and thyrotropin in the teleost, Xiphophorus maculatus. Gen. Comp. Endocrinol., 39: 467-474.

Suzuki, K., Kawauchi, H. and Nagahama, Y., 1988a. Isolation and characterization of two distinct gonadotropins from chum salmon pituitary glands. Gen. Comp. Endocrinol., 71: 292301.

Suzuki, K., Nagahama, Y. and Kawauchi, H., 1988b. Steroidogenic activities of two distinct salmon gonadotropins. Gen. Comp. Endocrinol., 71: 452-458.

Suzuki, K., Kanamori, A., Nagahama, Y. and Kawauchi, H., 1988c. Development of salmon GTH I and GTH II radioimmunoassays. Gen. Comp. Endocrinol., 71: 459-467.

Swanson, P., Dickhoff, W.W. and Gorbman, A., 1987. Pituitary thyrotropin and gonadotropin of coho salmon (Oncorhynchus kisutch): separation by chromatofocusing. Gen. Comp. Endocrinol., 65: 269-287.

Zohar, Y., 1988. Gonadotropin releasing hormones in spawning induction in teleosts: basic and applied considerations. In: Y. Zohar and B. Breton (Editors), Reproduction in Fish: Basic and Applied Aspects in Endocrinology and Genetics. INRA Press, Paris, pp. 47-62.

Zohar, Y. and Gordin, H., 1979. Spawning kinetics in the gilthead sea-bream, Sparus aurata (L.) after low doses of human chorionic gonadotropin. J. Fish. Biol., 15: 665-670.

Zohar, Y., Abraham, M. and Gordin, H., 1978. The gonadal cycle of the captivity-reared hermaphroditic teleost, Sparus aurata (L.) during the first two years of life. Ann. Biol. Anim. Biochim. Biophys., 18: 877-882.

Zohar, Y., Billard, R. and Weil, C., 1984. La reproduction de la daurada et du bar: le cycle sexuel et l'induction de la ponte. In: R. Billard and G. Barnabé (Editors), Aquaculture de Bar et des Sparidés. INRA Press, Paris, pp. 3-24.

Zohar, Y., Pagelson, G. and Tosky, M., 1988. Daily changes in reproductive hormone levels in the female gilthead seabream Sparus aurata at the spawning period. In: Y. Zohar and B. Breton (Editors), Reproduction in Fish - Basic and Applied Aspects in Endocrinology and Genetics. INRA Press, Paris, pp. 119-126.

Zohar, Y., Goren, A., Tosky, M., Pagelson, G., Leibovitz, D. and Koch, Y., 1989. The bioactivity of gonadotropin-releasing hormones and its regulation in the gilthead seabream, Sparus aurata; in vivo and in vitro studies. Fish Physiol. Biochem., 7: 59-67. 